\title{
Physical and Electrochemical Characterization of Nsutite
}

\author{
Rahul Singhal1, Jonathan Lembeck ${ }^{1,2}$, Peter C. K. LeMaire III ${ }^{3}$, Daniel Pereira1, Peter LeMaire ${ }^{1 *}$ \\ ${ }^{1}$ Department of Physics \& Engineering Physics, Central Connecticut State University, New Britain, CT, USA \\ ${ }^{2}$ Dynetics, 1002 Explorer Blvd, Huntsville, AL, USA \\ ${ }^{3}$ Department of Chemical Engineering, University of Pittsburgh, Pittsburgh, PA, USA \\ Email: *singhal@ccsu.edu
}

How to cite this paper: Singhal, R., Lembeck, J., LeMaire III, P.C.K., Pereira, D. and LeMaire, P. (2021) Physical and Electrochemical Characterization of Nsutite. American Journal of Analytical Chemistry, 12, 440-445. https://doi.org/10.4236/ajac.2021.1211027

Received: July 29, 2021

Accepted: November 21, 2021

Published: November 24, 2021

Copyright $\odot 2021$ by author(s) and Scientific Research Publishing Inc. This work is licensed under the Creative Commons Attribution International License (CC BY 4.0).

http://creativecommons.org/licenses/by/4.0/

\begin{abstract}
Manganese oxides are of interest as, among a number of other applications, supercapacitor materials for energy storage systems. Nsutite, a naturally occurring Manganese Oxide was studied as a possible high-volume source of materials for supercapacitor applications. X-ray diffraction and thermal analysis (DSC/TGA) measurements were carried out to characterize its physical properties, and Cyclic Voltametry and galvanostatic charge-discharge measurements were carried out to obtain its electrochemical properties. The XRD and thermal results support transitions of nsutite, upon heating which were attributed to conversion to $\mathrm{MnO}_{2}$, and to $\mathrm{Mn}_{2} \mathrm{O}_{3}$ and eventually to $\mathrm{Mn}_{3} \mathrm{O}_{4}$. The electrochemical results of the as mined material show supercapacitance behaviour, suggesting that nsutite, with some heat processing, is to be a promising high-volume source of manganese oxides for supercapacitor applications.
\end{abstract}

\section{Keywords}

Nsutite, Manganese Oxides, Supercapacitors, Cyclic Voltammetry, Specific Capacitance

\section{Introduction}

Nsutite is a naturally occurring Manganese Oxide of the composition $\mathrm{Mn}_{1-\mathrm{x}}^{4+} \mathrm{Mn}_{\mathrm{x}}^{2+} \mathrm{O}_{2-2 \mathrm{x}}(\mathrm{OH})_{2 \mathrm{x}}$ where $\mathrm{x}=0.06-0.07$ [1]. In recent years, manganese oxides have been the subject of numerous studies because of their applications in energy storage systems, as catalysts for specific applications, as purification agents in drinking water, and the steel industry. In addition to battery applications, manganese oxides have been found to be promising in electrochemical supercapaci- 
tors [2] [3] [4] [5]. In this paper, we performed physical, thermal, and electrochemical characterization of nsutite material for possible supercapacitor applications.

\section{Experimental}

We acquired samples of various grades of nsutite materials from the Ghana Manganese Company, Nsuta, Ghana. Nsutite is named after the village, Nsuta, where the material was first discovered.

Physical characterizations of the acquired nsutite material were carried out by powder X-ray diffraction (XRD) studies using a Rigaku Mini flex-II diffractometer. The thermal analysis, (Differential Scanning Calorimetry/Thermogravimetry) was carried out using a TA Instruments STA Q600.

The electrochemical properties of nsutite were studied using a Squidstat plus potentiostat (Admiral Instruments, USA). The electrochemical measurements were conducted in standard three-electrode configuration, where a platinum wire/foil and an $\mathrm{Ag} / \mathrm{AgCl}$ electrode were used as a counter and a reference electrode respectively. Slurries of nsutite coated onto nickel foam were used as working electrode. All the electrochemical measurements were performed in $1 \mathrm{M}$ $\mathrm{Na}_{2} \mathrm{SO}_{4}$ solution. The slurries were prepared by mixing $80 \mathrm{wt} \%$ of the nsutite, 10 wt $\%$ of carbon black and $10 \mathrm{wt} \%$ of Polytetrafluoroethylene (PTFE) binder, using ethanol as a solvent. After thoroughly mixing, the slurry was applied to a pre-cleaned nickel electrode. The mass loading of the material was obtained by measuring the mass of the nickel foam before and after electrode preparation, using an analytical balance. Electrochemical properties of the synthesized samples were investigated using cyclic voltammetry $(\mathrm{CV})$ and galvanostatic chargedischarge studies.

\section{Results}

Figure 1 shows the XRD patterns of nsutite annealed at three temperatures, $350^{\circ} \mathrm{C}, 500^{\circ} \mathrm{C}$ and $650^{\circ} \mathrm{C}$. The results support reports in the literature of the various transitions as the material is heated [6].

From Figure 2, the cyclic voltammogram of nsutite materials showed capacitive behaviour at various scan rates from $20 \mathrm{mV} / \mathrm{s}$ to $200 \mathrm{mV} / \mathrm{s}$. Figure 2 also shows the rectangular shaped cyclic voltammogram typical of pseudocapacitive oxides [7], indicating that nsutite has pseudocapacitive properties. The specific capacitance of the samples was calculated using the following equation:

$$
C_{s p}=\int I \cdot \mathrm{d} V / \Delta V \times \vartheta \times m
$$

where, $I$ is the current, $\Delta V$ is the potential window, $\vartheta$ represents the scan rate and $m$ is the mass of the samples. The specific capacitance of nsutite obtained from the cyclic voltammetry studies is given in Table 1 .

The specific capacitance of nsutite materials electrodes was calculated from the galvanostatic charge-discharge measurements, using the following equation: 


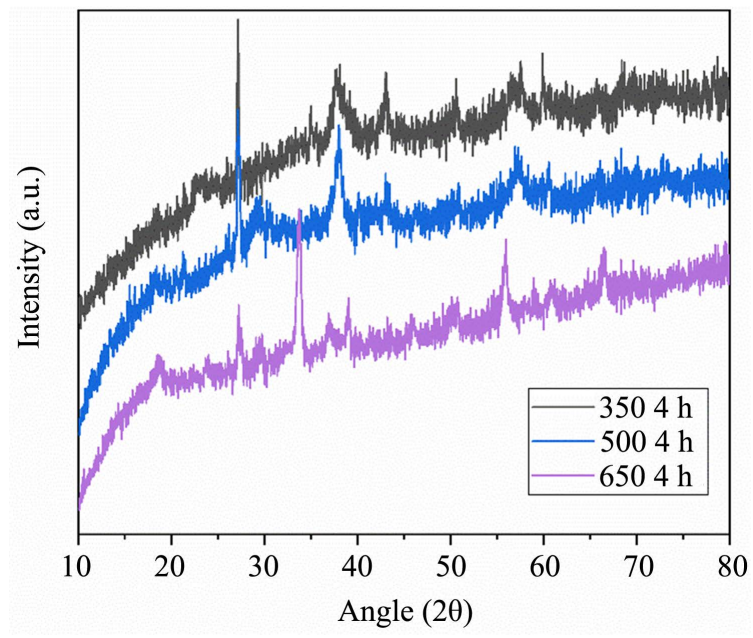

Figure 1. X-ray diffraction pattern of nsutite, annealed at various temperatures.

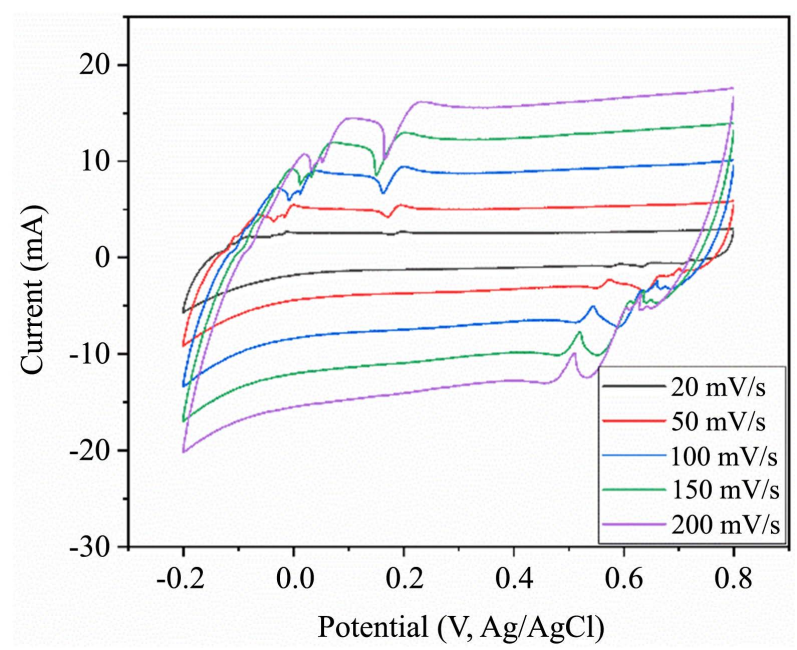

Figure 2. Cyclic voltammogram of nsutite at various scan rate.

Table 1. Specific capacitance of nsutite from cyclic voltammetry studies.

\begin{tabular}{ccc}
\hline S. No. & Scan rate $(\mathrm{mV} / \mathrm{s})$ & Specific capacitance $(\mathrm{F} / \mathrm{g})$ \\
\hline 1 & 20 & 19.29 \\
2 & 50 & 16.70 \\
3 & 100 & 14.57 \\
4 & 150 & 13.19 \\
5 & 200 & 12.10 \\
\hline
\end{tabular}

$$
C_{s p}=I \times \Delta t / \Delta V \times m
$$

where, $I$ is the discharge current (A), $\Delta t$ is the discharge time (s), $\Delta V$ is the potential window $(\mathrm{V})$ and $m$ is the mass $(\mathrm{g})$ of the samples. Figure 3 represents the galvanostatic charge discharge of nsutite electrodes and the specific capacitance of nsutite at various current densities is given in Table 2. 

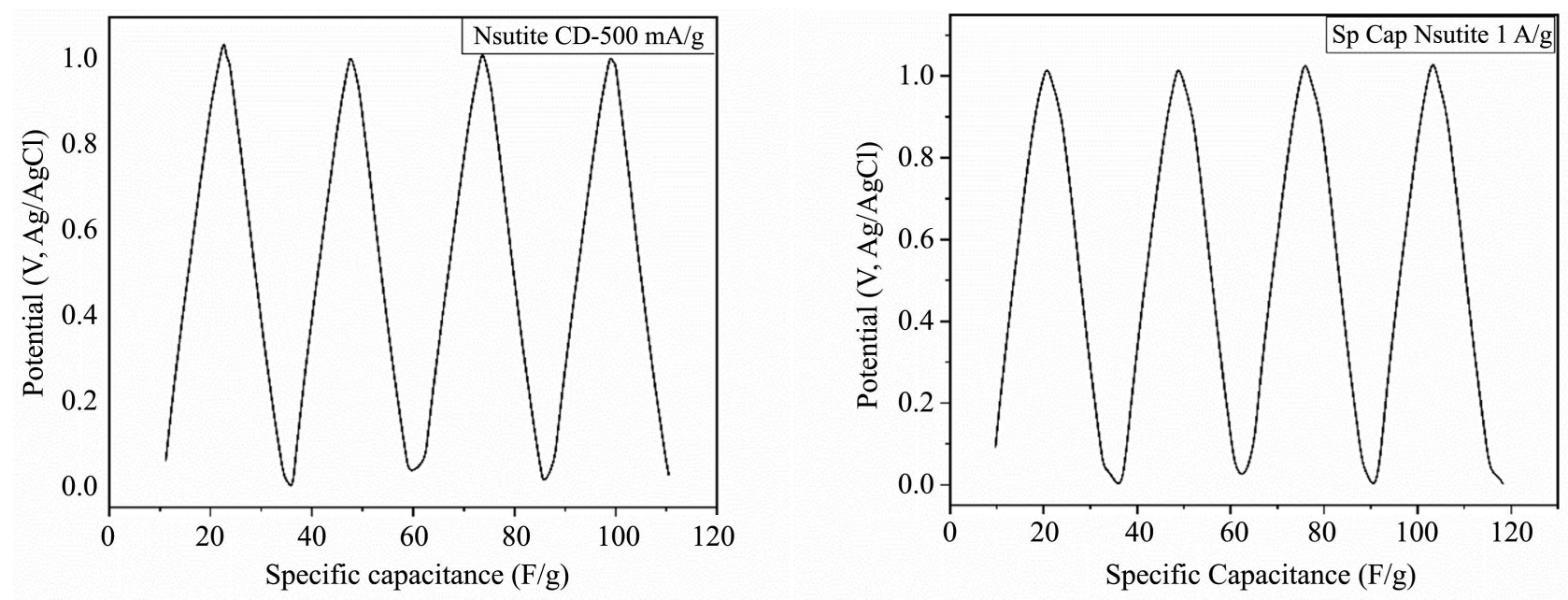

Figure 3. Galvanostatic charge discharge of nsutite.

Table 2. Specific capacitance of nsutite at various current densities.

\begin{tabular}{|c|c|c|}
\hline No. of cycle & $\begin{array}{l}\text { Specific capacitance }(\mathrm{F} / \mathrm{g}) \\
\text { at current density } 500 \mathrm{~mA} / \mathrm{g}\end{array}$ & $\begin{array}{c}\text { Specific capacitance }(\mathrm{F} / \mathrm{g}) \\
\text { at current density } 1 \mathrm{~A} / \mathrm{g}\end{array}$ \\
\hline 1 & 13.03 & 15.08 \\
\hline 2 & 11.5 & 14.16 \\
\hline 3 & 14.5 & 14.276 \\
\hline 4 & 11.5 & 15.107 \\
\hline Average Specific Capacitance & 12.63 & 14.65 \\
\hline
\end{tabular}

It can be seen from Table 2 that average specific capacitance of nsutite materials was found to be as $12.63 \mathrm{~F} / \mathrm{g}$ and $14.65 \mathrm{~F} / \mathrm{g}$ at current density of $500 \mathrm{~mA} / \mathrm{g}$ and $1 \mathrm{~A} / \mathrm{g}$, respectively. It was reported earlier that the specific capacitance of pure $\mathrm{MnO}_{2}$ was $300 \mathrm{~F} / \mathrm{g}$ and $290 \mathrm{~F} / \mathrm{g}$ at current density of $500 \mathrm{~mA} / \mathrm{g}$, and $1 \mathrm{~A} / \mathrm{g}$, respectively [8]. The low specific capacitance of nsutite materials compared to pure $\mathrm{MnO}_{2}$ can be ascribed to the structural report that nsutite is not a pure $\mathrm{MnO}_{2}$ material and may contain other manganese oxides [9] and impurities present in the nsutite materials.

Figure 4 shows the differential scanning calorimetry (DSC) and Thermogravimetric Analysis (TGA) of nsutite. The DSC and TGA results show three transitions between $200^{\circ} \mathrm{C}$ and $1000^{\circ} \mathrm{C}$. The first transition at $351^{\circ} \mathrm{C}$ and the corresponding mass loss can be attributed to loss of physiosorbed and chemisorbed water, and formation of $\mathrm{MnO}_{2}$ with $4.5 \%$ mass loss. This is followed by the reduction to $\mathrm{Mn}_{2} \mathrm{O}_{3}$ [9] [10] at about $583^{\circ} \mathrm{C}$ with a mass loss of about $5.9 \%$. The thermal transformation of nsutite to $\mathrm{Mn}_{2} \mathrm{O}_{3}$ results in about $10.4 \%$ mass loss. This result is in agreement with results of about $11 \%$ obtained by Mohapatra et al. [9]. Finally, we observed a transformation from $\mathrm{Mn}_{2} \mathrm{O}_{3}$ to $\mathrm{Mn}_{3} \mathrm{O}_{4}$ with a mass loss of about $3.1 \%$ at about $870^{\circ} \mathrm{C}$. The observed mass loss of $3.3 \%$, is in agreement with stoichiometric values of conversion of $\mathrm{Mn}_{2} \mathrm{O}_{3}$ to $\mathrm{Mn}_{3} \mathrm{O}_{4}$ given by 


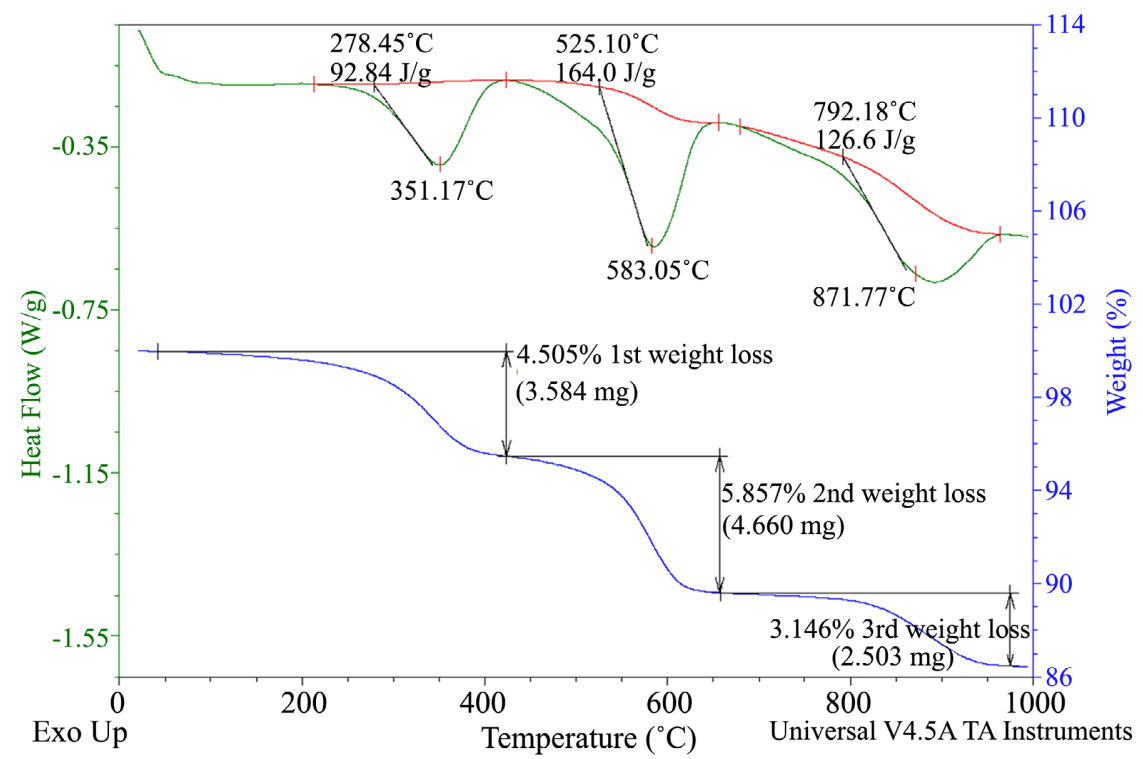

Figure 4. DSC (heat flow) and TGA (weight \%) of nsutite vs. temperature.

$$
6 \mathrm{Mn}_{2} \mathrm{O}_{3} \rightarrow 4 \mathrm{Mn}_{3} \mathrm{O}_{4}+\mathrm{O}_{2}
$$

and is due to loss of oxygen. The suggestion by Bish et al. [10] that heating reduces Mn to lower valence states is also in line with our observed thermal transformations.

In our future work, we plan to use our thermal analysis results as a guide and will anneal the naturally acquired nsutite materials at the transition temperatures and study the physical and electrochemical behavior of the annealed samples. This work is significant because nsutite is naturally occurring and is readily available, and so its thermal modification for supercapacitor application will be highly beneficial in the search for readily available high-volume materials for such energy storage systems.

\section{Acknowledgements}

The financial support received from the CCSU-AAUP Faculty research grant is highly acknowledged.

\section{Conflicts of Interest}

The authors declare no conflicts of interest regarding the publication of this paper.

\section{References}

[1] Post, J.E. (1999) Manganese Oxide Minerals: Crystal Structures and Economic and Environmental Significance. PNAS, 96, 3447-3454.

[2] Kim, H. and Popov, B.N. (2003) Synthesis and Characterization of $\mathrm{MnO}_{2}$-Based Mixed Oxides as Supercapacitors. Journal of The Electrochemical Society, 150, D56. https://doi.org/10.1149/1.1541675

[3] Gambou-Bosca, A. and Belanger, D. (2016) Electrochemical Characterization of 
$\mathrm{MnO}_{2}$-Based Composite in the Presence of Salt-in-Water and Water-in-Salt Electrolytes as Electrode for Electrochemical Capacitors. Journal of Power Sources, 326, 595-603. https://doi.org/10.1016/j.jpowsour.2016.04.088

[4] Mohammadi, N., Pourreza, K., Adeh, N.B. and Omidvar M. (2021) Defective Mesoporous Carbon $/ \mathrm{MnO}_{2}$ Nanocomposite as an Advanced Electrode Material for Supercapacitor Application. Journal of Alloys and Compounds, 883, Article ID: 160874. https://doi.org/10.1016/j.jallcom.2021.160874

[5] Zhang, G.N., Zhang, J.H., Yang, H.J. and Li, X.F. (2022) In-Situ Redox Reaction Derived Porous Nanosheets of $\mathrm{MnO}_{2}$ for Supercapacitors. Materials Letters, 306, Article ID: 130858. https://doi.org/10.1016/j.matlet.2021.130858

[6] Faulring, G.M. (1965) Unit Cell Determination and Thermal Transformations of Nsutite. The American Mineralogist, 50, 170-179.

[7] Brousse, T., Belanger, D. and Long, J.W. (2015) To Be or Not to Be Pseudocapacitive? Journal of The Electrochemical Society, 162, A5185.

https://doi.org/10.1149/2.0201505jes

[8] Singhal, R., Fagnoni, J., Thorne, D., LeMaire, P.K., Martinez, X., Zhao, C., Gupta, R.K., Uhl, D., Scanley, E., Broadbridge, C.C. and Manivannan, M. (2019) Study of $\mathrm{MnO}_{2}$-Graphene Oxide Nanocomposites for Supercapacitor Applications. MRS Advances, 4, 777-782. https://doi.org/10.1557/adv.2019.86

[9] Mohapatra, B.K., Nayak, B.R. and Sahoo, R.K. (1995) Characteristics of Nsutite ( $\gamma$ $\mathrm{MnO}_{2}$ ) in Goriajhar Manganese Deposit, Gangpur Group, India. Journal of Mineralogy, Petrology and Economic Geology, 90, 280-287. https://doi.org/10.2465/ganko.90.280

[10] Bish, D.L. and Post, J.E. (1989) Thermal Behavior of Complex, Tunnel-Structure Manganese Oxides. American Mineralogist, 74, 177-186. 